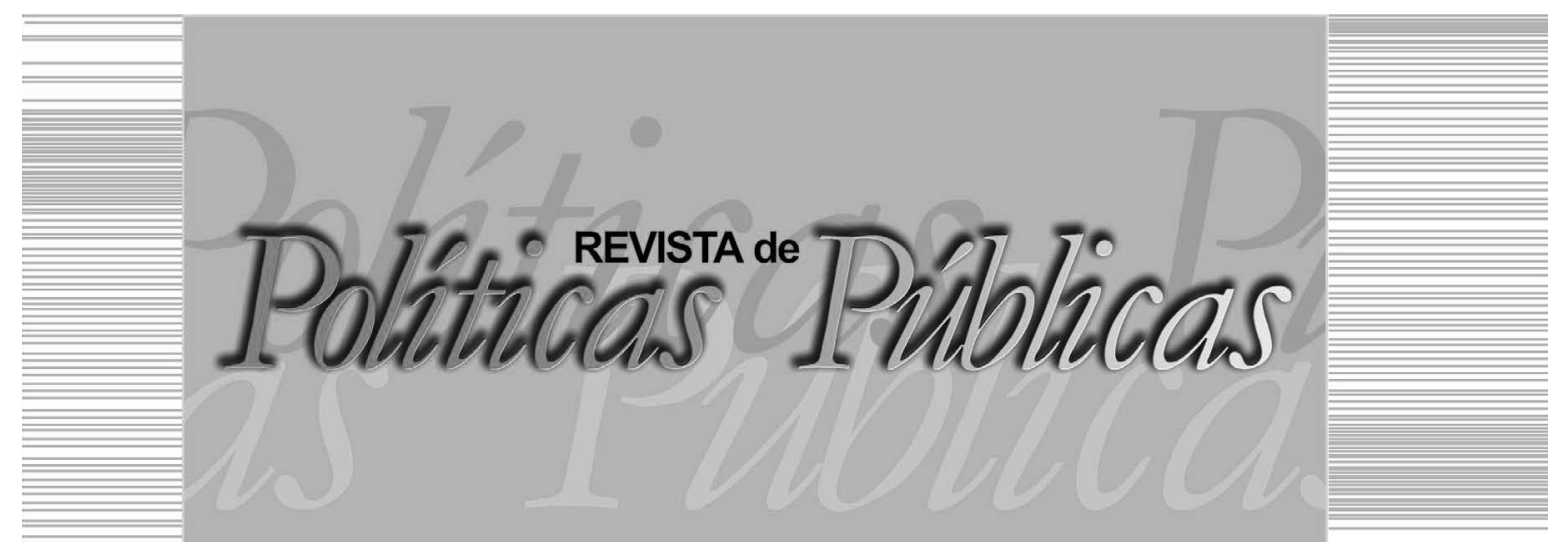

\title{
MODIFICAÇÕES LEGISLATIVAS E IMPACTOS \\ NOS ROYALTIES E NA PARTICIPACÃO ESPECIAL DESTINADOS AOS ÓRGÃOS DA ADMINISTRAÇÃO DIRETA'
}

\author{
Hirdan Katarina de Medeiros Costa \\ André Felipe Simões ${ }^{2}$ \\ Edmilson Moutinho dos Santos ${ }^{3}$ \\ Isabela Morbach Machado e Silva
}

\section{Resumo}

O objetivo do artigo é descrever e analisar o volume de recursos financeiros, proveniente do pagamento de royalties e/ou participação especial, gerados pela produção de petróleo e recebidos pelo Comando da Marinha, Ministério de Ciência, Tecnologia e Inovação, Ministério de Minas e Energia e Ministério de Meio Ambiente, dos Recursos Hídricos e da Amazônia Legal. O artigo verifica,

1 Advogado, Doutora em Ciências pelo Programa de Pós-Graduação em Energia do Instituto de Energia e Ambiente (IEE) da Universidade de São Paulo (USP), Professora Colaboradora e Orientadora Plena no mesmo Programa/USP. E-mail: hirdan@usp.br

2 Engenheiro Metalúrgico, Doutor em Planejamento Energético pela Universidade Federal do Rio de Janeiro (UFRJ) e pós-doutorado em Planejamento de Sistemas Energéticos pela Universidade Estadual de Campinas (Unicamp), Professor Associado da USP. E-mail: afsimoes@usp.br

3 Economista e Engenheiro Eletrotécnico, Doutor em Economia da Energia pelo Instituto Francês do Petróleo e Université de Bourgogne, Professor Associado do IEE/USP E-mail: edsantos@iee.usp.br

4 Advogada, Pesquisadora do Projeto "Evaluation of environmental impact of CCS activities in Brazil and legal aspects" do CO2 Abatement Programme do Research Center for Gas Innovation, Doutoranda em Energia no IEE/USP. E-mail: isabelamorbach@usp. br / Universidade de São Paulo - USP: Avenida Professor Luciano Gualberto, 1289, Cidade Universitária, Butantã - São Paulo. CEP: 05508-010. 
ainda, o volume de royalties e de participação especial destinado ao Fundo Social, criado pela Lei 12.351/2010. Destaca como no período de 1999-2015, as modificações legais alteraram os destinos desses recursos financeiros entre os beneficiários enquadrados como órgãos da Administração Direta e o Fundo Social. Conclui que os resultados mostram queda significativa nas receitas percebidas pelos órgãos da Administração Pública Direta, e elevação robusta das receitas do Fundo Social.

Palavras-chaves: Royalties, participação especial, órgãos da administração pública direta, fundo Social, dilemas entre despesas e poupanças públicas.

\title{
LEGISLATIVE MODIFICATIONS AND IMPACT ON ROYALTIES AND IN THE SPECIAL PARTICIPATION DESTINED TO DIRECT MANAGEMENT AGENCIES
}

\begin{abstract}
The aim of the paper is to describe and analyze the amount of financial resources from payments of royalties and special participation in oil production, and received by the Navy Command, the Ministry of Science, Technology and Innovation,the Ministry of Mines and Energy and the Ministry of Environment, Hydric Resources and legal Amazon. The amount of royalties and special participation payments destined to the Social Fund, created by Law 12.351/2010, is also assessed. By covering up the long-term historical context from 1999 to 2015 , it is pointed out as the legal changes altered the destinies of these funds from beneficiaries classified as organs of direct administration to the Social Fund. The results show a significant decrease in revenues perceived by the agencies of the direct public administration, and robust increase in revenues of the Social Fund.

Keywords: Royalties, special participation, government agencies from direct public administration, social fund, dilemma between expenditure and public savings.
\end{abstract}

\section{INTRODUÇÃO}

A partir de 1995, com a edição da Emenda Constitucional no 9, de 9 de novembro, a legislação da indústria de petróleo e gás natural (hidrocarbonetos) no Brasil sofreu uma série de modificações. Foi promulgada a Lei $\mathrm{n}^{0}$ 9.784, de 6 de agosto de 1997 (BRASIL, 1999), conhecida como a Lei do Petróleo; posteriormente, diversas normas alteraram o texto original, porém sem mudanças significativas nas bases contratuais do regime de concessão e de remuneração do poder concedente. 
MODIFICAÇÕES LEGISLATIVAS E IMPACTOS NOS ROYALTIES E NA PARTICIPAÇÃO ESPECIAL DESTINADOS AOS ÓRGÃOS DA ADMINISTRAÇÃO DIRETA

Após as descobertas na região conhecida como Pré-Sal, o Governo Federal anunciou a revisão da Lei $n^{\circ}$ 9.784/1997, o que culminou na promulgação da Lei ${ }^{\circ} 12.351$, de 22 de dezembro de 2010, que dentre outras matérias, tratou do regime de partilha de produção em áreas do Pré-Sal e em áreas consideradas de interesse estratégico, bem como instituiu o Fundo Social (FS), dispondo de sua estrutura e fontes de recurso.

Em matéria de royalties, foi promulgada a Lei $\mathrm{n}^{\circ} 12.734$, de 30 de novembro de 2012, que teve inúmeros artigos vetados pela Presidente Dilma Roussef que, por sua vez, editou a Medida Provisória (MPV) n ${ }^{\circ} 592$ de 3 de dezembro de 2012 para dispor sobre esse assunto. A MPV no 592/2012 perdeu a eficácia por causa do término do prazo de vigência, em 12 de maio de 2013. (BRASIL, 2009). Em 15 de março de 2013, por meio de Ações Diretas de Inconstitucionalidade (ADI) promovidas pelos principais Estados beneficiários dos royalties ( ${ }^{\circ} \mathrm{ADIs} 4916,4917,4918$ e 4920²), de relatoria da Ministra Carmen Lúcia, foi concedida liminar isolada para suspender a aplicação dos critérios de rateio criados pela nova Lei $\mathrm{n}^{\mathrm{0}} 12.734 / 2012$.

Diante dessas modificações legislativas, o objetivo do artigo é analisar o volume de royalties recebido pelo Comando da Marinha (CM) e o Ministério de Ciência, Tecnologia e Inovação (MCTI) e de participação especial percebido pelo Ministério de Minas e Energia (MME) e Ministério de Meio Ambiente, dos Recursos Hídricos e da Amazônia Legal (MMA), todos enquadrados como órgãos da Administração Pública Direta. Verifica-se, ainda, o volume de royalties e de participação especial destinado ao FS, criado pela Lei ${ }^{\circ}$ 12.351/2010. (BRASIL, 2010c).

Na sequência dessa introdução, a seção 2 traz um exame geral dos artigos desses dois diplomas legais e pontua as respectivas áreas de destinação dos royalties e participação especial. A seção 3 aborda as análises realizadas a partir da observação da relação entre o volume de royalties recebidos pelo CM e o MCTI e de participação especial percebido pelo MME e MMA, assim como o FS, criado pela Lei $n^{\circ} 12.351 / 2010$. As considerações finais são apresentadas na seção 4.

A metodologia compreende a descrição da legislação sobre distribuição dos royalties e participação especial. Também, aborda-se o contexto histórico de alteração da Lei do Petróleo para a Lei $\mathrm{n}^{\circ} 12.351 / 2010$ e Lei $\mathrm{n}^{\circ}$ 12.374/2012 em matéria de distribuição de 
royalties, assim como a análise da representatividade das modificações legais em termos de recebimento de receitas oriundas do Exploração e Produção (E\&P) para os beneficiários enquadrados como órgão da Administração Direta e FS. Essa análise abarcará o período de 1999/2015.

\section{MODIFICAÇÕES LEGISLATIVAS SOBRE DISTRIBUIÇÃO DOS ROYALTIES E PARTICIPAÇÃO ESPECIAL}

\subsection{Redação original da Lei do Petróleo e da Lei n 7.990/1989 e 0 tema royalties e participação especial}

O modelo de distribuição de royalties de petróleo e gás natural, tratado neste item, é aquele previsto originalmente na Lei do Petróleo e na Lei $\mathrm{n}^{\circ} 7.990$, de 28 de novembro de 1989 . Ou seja, trata-se de redação anterior às alterações dadas pelas Leis $n^{\circ}$ 12.351/2010 e 12.734/2012, respectivamente. O objetivo é apresentar uma base histórica para melhor entendimento dos efeitos dessas modificações legislativas quanto ao recebimento de receitas de exploração de petróleo e gás pelos órgãos da Administração Pública Federal e para o FS.

$\mathrm{O}$ art. $47^{\circ}$ da Lei do Petróleo definia o montante de $10 \%$ da produção de petróleo e gás natural como valor a ser pago a título de royalties. Quanto aos valores excedentes a $5 \%$ da produção, as regras de distribuição que incidiam eram as do art. $49^{\circ}$ dessa lei. No que tange à parcela de até $5 \%$ da produção (parcela não excedente a 5\%), as regras de distribuição eram as constantes da Lei ${ }^{\circ}$ 7.990/1989. (BRASIL, 1989). Registrava-se, portanto, a existência de dois diferentes sistemas de distribuição dos recursos provenientes dos royalties de petróleo e gás natural sob o contrato de concessão. (COSTA, 2012).

Nessa distribuição, o MCTI percebia $50 \%$ dos valores relativos à parcela excedente a $5 \%$ da produção em terra e na Plataforma Continental, enquanto o $\mathrm{CM}$ percebia $15 \%$ dos valores relativos à parcela excedente a $5 \%$ da produção na Plataforma Continental. (BRASIL, 1999).

No tocante à distribuição da parcela de até $5 \%$ da produção, conforme orientado pelos incisos do art. $7^{\circ}$ da Lei $n^{\circ} 7.990 / 1989$, o 
MODIFICAÇÕES LEGISLATIVAS E IMPACTOS NOS ROYALTIES E NA PARTICIPAÇÃO ESPECIAL DESTINADOS AOS ÓRGÃOS DA ADMINISTRAÇÃO DIRETA

CM percebia $20 \%$ sobre parcela não excedente ou até $5 \%$ da produção na Plataforma Continental. (BRASIL, 1989, 1999). Sob a égide de tais ponderações, o tópico a seguir analisa a sistemática de distribuição de royalties inerente à tramitação da Lei n ${ }^{0}$ 12.351/2010.

\subsection{Histórico da Lei $n^{0} \mathbf{1 2 . 3 5 1 / 2 0 1 0}$}

Em 22 de dezembro de 2010, o Presidente da República à época, Luis Inácio Lula da Silva, sancionou a Lei nº12.351/2010 com veto ao $\S 2^{\circ}$ do art. $47^{\circ}$ e ao artigo $64^{\circ 3}$, por entender que a redação final contrariava o interesse público, em razão da indefinição de fórmula ou de alíquota para obtenção do montante total dos recursos provenientes dos royalties, bem como da não determinação do percentual de participação correspondente para a União, Estados, Distrito Federal e Municípios. (BRASIL, 2007).

Com isso, a Presidência da República submeteu o Projeto de Lei (PL) n ${ }^{\circ} 8.051$, de 31 de dezembro de 2010 ao Congresso Nacional, justificando-se, sobretudo, pela lacuna oportunizada por meio de referido veto presidencial e pela inviabilização de licitações sob o regime de partilha sem as definições do percentual de royalties sobre a produção de petróleo e gás natural. (BRASIL, 2010a).

Segundo o proposto, os royalties deveriam ser pagos mensalmente a partir da data relativa ao início da produção comercial, e o seu valor correspondente seria de $15 \%$ sobre a produção. Na divisão dos royalties constante do $\mathrm{PL} \mathrm{n}^{\circ} 8.051 / 2010$, os órgãos da administração direta da União não são mais contemplados como beneficiários. (BRASIL, 2010a). O FS criado pela Lei $\mathrm{n}^{\circ} 12.351 / 2010$ passa a ser o beneficiário, cabendo ao Poder Executivo destinar parcelas para os órgãos da administração direta da União, definidas em regulamento posterior.

\subsection{A continuidade das discussões e a promulgação da Lei $\mathbf{n}^{0}$ 12.734/2012}

Enquanto o PL ${ }^{\circ} 8.051 / 2010$ somente propunha a modificação da Lei $\mathrm{n}^{\circ}$ 12.351/2010, o PL n ${ }^{\circ} 2.565$, de 24 de outubro de 2011 (Projeto de Lei do Senado - PLS n ${ }^{\circ}$ 448/2011), transformado na Lei $\mathrm{n}^{\mathrm{o}} 12.734 / 2012$, alterou além da Lei $\mathrm{n}^{\circ} 12.351 / 2010$, a Lei do Petróleo. A alíquota na Lei do Petróleo permanece 10\% sobre a 
produção, já na Lei do Pré-Sal (BRASIL, 2010b) foi para 15\% sobre a produção.

A Lei $n^{\circ} 12.734 / 2012$, também, não contempla os órgãos da administração direta da União como beneficiários diretos dos royalties, todavia, o FS passa a ser beneficiário com $22 \%$ da alíquota de $15 \%$ dentro do modelo de Partilha de Produção. (BRASIL, 2012).

No que concerne à alteração da Lei do Petróleo, a Lei ${ }^{\circ}$ $12.734 / 2012$, quando aprovada pelo Congresso, prescrevia a imediata aplicação de novos percentuais de distribuição. (BRASIL, 2012). Essa foi a parte controversa dessa Lei, e que foi objeto de veto da Presidência da República, posteriormente, da MPV no 592/2012, que meses depois foi derrubada pelos congressistas da bancada oposicionista e a Presidência republicou os dispositivos vetados, que posteriormente tiveram a aplicabilidade suspensa pela Ação Direta de Inconstitucionalidade (ADI) $\mathrm{n}^{\circ} 4917$.

No modelo de concessão, o montante significativo da modificação legislativa se concentrou na área offshore, com o incremento da participação de estados e municípios não produtores, através de fundos (dentro dos critérios do Fundos de Participação dos Estados - FPE e Fundos de Participação dos Municípios - FPM). Isso, considerando tanto as formas de repartição limitadas a $5 \%$ da produção, quanto aquelas baseadas no modelo de distribuição do excedente a $5 \%$ da produção. (BRASIL, 2012). O FS passou a ser o beneficiário com $20 \%$ do montante de $10 \%$, deduzidas parcelas destinadas aos órgãos da administração direta da União, nos termos de regulamento do Poder Executivo. (BRASIL, 2012).

Por outro lado, no que tange ao onshore do modelo de concessão, não há modificação na sistemática de até $5 \%$ da produção. (BRASIL, 2012). Somente no modelo do excedente a 5\% é que ocorre a inserção do FS como beneficiário, deduzidas parcelas destinadas aos órgãos da administração direta da União, nos termos de regulamento do Poder Executivo, e, consequentemente, a diminuição dos percentuais dos outros destinatários. (BRASIL, 2012).

No que diz respeito à repartição de Receitas para União, a Quadro 1 facilita a visualização das alterações legislativas: 
MODIFICAÇÕES LEGISLATIVAS E IMPACTOS NOS ROYALTIES E NA PARTICIPAÇÃO ESPECIAL DESTINADOS AOS ÓRGÃOS DA ADMINISTRAÇÃO DIRETA

\begin{tabular}{|c|c|c|c|c|c|c|c|}
\hline \multirow{2}{*}{$\begin{array}{c}\text { Origem } \\
\text { das } \\
\text { receitas }\end{array}$} & \multirow{2}{*}{$\begin{array}{l}\text { Destino das } \\
\text { receitas }\end{array}$} & \multicolumn{2}{|c|}{ Partilha } & \multicolumn{2}{|c|}{$\begin{array}{c}\text { Concessão } \\
\text { (5\% obrigatório) }\end{array}$} & \multicolumn{2}{|c|}{$\begin{array}{l}\text { Concessão } \\
(5 \% \text { e } 10 \%)\end{array}$} \\
\hline & & $\begin{array}{l}\text { Norma } \\
\text { Atual }\end{array}$ & $\begin{array}{c}\text { Norma } \\
\text { Anterior }\end{array}$ & $\begin{array}{c}\text { Norma } \\
\text { Atual }\end{array}$ & $\begin{array}{c}\text { Norma } \\
\text { Anterior }\end{array}$ & $\begin{array}{c}\text { Norma } \\
\text { Atual }\end{array}$ & $\begin{array}{c}\text { Norma } \\
\text { Anterior }\end{array}$ \\
\hline \multirow{2}{*}{ 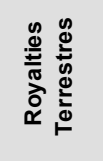 } & Fundo Social & $15 \%$ & $\begin{array}{c}\text { Não } \\
\text { tratava }\end{array}$ & 0 & 0 & $25 \%$ & $\begin{array}{l}\text { Não } \\
\text { tratava }\end{array}$ \\
\hline & $\begin{array}{c}\text { Ministério da } \\
\text { Marinha }\end{array}$ & 0 & $\begin{array}{c}\text { Não } \\
\text { tratava }\end{array}$ & $\begin{array}{l}\text { Não } \\
\text { trata }\end{array}$ & 0 & $\begin{array}{l}\text { Não } \\
\text { trata }\end{array}$ & $25 \%$ \\
\hline \multirow{3}{*}{ 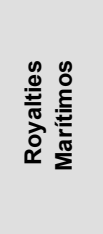 } & Fundo Social & $22 \%$ & $\begin{array}{c}\text { Não } \\
\text { tratava }\end{array}$ & $20 \%$ & 0 & $20 \%$ & $\begin{array}{l}\text { Não } \\
\text { tratava }\end{array}$ \\
\hline & $\begin{array}{l}\text { Ministério da } \\
\text { Marinha }\end{array}$ & 0 & $\begin{array}{c}\text { Não } \\
\text { tratava }\end{array}$ & $\begin{array}{l}\text { Não } \\
\text { trata }\end{array}$ & $20 \%$ & $\begin{array}{l}\text { Não } \\
\text { trata }\end{array}$ & $15 \%$ \\
\hline & $\begin{array}{c}\text { Ministério da } \\
\text { Ciência e } \\
\text { Tecnologia }\end{array}$ & 0 & $\begin{array}{c}\text { Não } \\
\text { tratava }\end{array}$ & $\begin{array}{l}\text { Não } \\
\text { trata }\end{array}$ & $\begin{array}{l}\text { Não } \\
\text { tratava }\end{array}$ & $\begin{array}{l}\text { Não } \\
\text { trata }\end{array}$ & $25 \%$ \\
\hline
\end{tabular}

Fonte: Elaboração própria.

\subsection{Ação Direta de Inconstitucionalidade (ADI) 4917}

Diante do cenário de superação dos vetos da Presidência da República na Lei 12.734/2012, em 15 de março de 2013, o Governador do Estado do Rio de Janeiro à época, Sérgio Cabral Filho, ajuizou a ADI no Supremo Tribunal Federal (STF), com pedido de medida cautelar. Foram impugnados, especificamente, os artigos $42^{\circ}$-B; $42^{\circ}$-C; $48^{\circ}$, II; $49^{\circ}$, II; $49^{\circ}-\mathrm{A} ; 49^{\circ}-\mathrm{B} ; 49^{\circ}$-C; $50^{\circ} ; 50^{\circ}$-A; $50^{\circ}$-B; $50^{\circ}$-C; $50^{\circ}$-D; e $50^{\circ}$-E da Lei ${ }^{\circ} 9.478$, de 6 de agosto de 1997 , todos com a redação expressa pela Lei Federal n ${ }^{0}$ 12.734/2012.

Os argumentos aduzidos para o pleito de declaração de inconstitucionalidade se concentram em três pontos. $\mathrm{O}$ primeiro se refere à quebra do pacto federativo consistente na contrapartida ao regime diferenciado do Imposto sobre Operações relativas à Circulação de Mercadorias e sobre Prestações de Serviços de Transporte Interestadual e Intermunicipal e de Comunicação (ICMS) incidente sobre o petróleo. O segundo se relaciona à interpretação do art. $20, \S 1^{\circ}$ da Constituição Federal (CF), que, segundo o autor da ação, tem um viés de compensação pelo ônus ambiental e de demanda por serviços públicos gerados pela exploração do recurso natural. E, finalmente, o terceiro argumento gira em torno da absoluta ilegitimidade da aplicação do novo regime às concessões firmadas anteriormente à promulgação da Lei n ${ }^{0}$ 12.734/2012. 
A Ministra Carmen Lúcia passou a examinar cada um dos argumentos levantados pelo autor na inicial. (BRASIL, 2013b). Quanto ao princípio federativo, a Ministra entendeu que o $\S 1^{\circ}$ do art. $20^{\circ}$ da CF contém norma de eficácia limitada, sendo que na legislação superveniente (Lei no 9.478/1997), o Estado e o Município, em cujo território se tenha a exploração de petróleo ou de gás natural ou que seja confrontante com área marítima, são titulares do direito assegurado na regra constitucional.

Destarte, no segundo ponto, a Ministra apreendeu pela interpretação do $\S 1^{\circ}$ do art. $20^{\circ}$ da $\mathrm{CF}$, que os direitos das entidades federadas decorrem de suas condições territoriais e dos ônus que têm que suportar, assim como, a participação no resultado da exploração ajusta-se ao modelo tributário da alínea b, inciso $X, \S 2^{\circ}$ do art. $155^{\circ}$ da $\mathrm{CF}$, segundo o qual não incidirá o ICMS sobre as operações que destinem petróleo e derivados, incluindo eletricidade, a outros Estados.

No que diz respeito à aplicação do novo regime aos contratos já firmados, a Ministra Carmen Lúcia, nem sequer cogitou a possibilidade de incidência das novas regras a atos jurídicos aperfeiçoados nos termos da legislação vigente ao tempo de sua prática, pois os institutos do direito adquirido, do ato jurídico perfeito e da coisa julgada são desdobramentos do princípio da segurança jurídica. (BRASIL, 2013b).

Pelos juízos expostos, a Ministra Carmen Lúcia deferiu a medida cautelar requerida com a finalidade de resguardar os direitos dos cidadãos dos Estados e Municípios que se afirmam atingidos em sua capacidade financeira e políticas, bem como em seus direitos constitucionais. (BRASIL, 2013b).

Com os vetos rejeitados pelo Congresso, a Lei ${ }^{\circ}$ 12.734/2012 foi republicada e entrou em vigor, na sua integralidade, entretanto, os dispositivos citados pela Ministra estão suspensos até que seja proferida decisão de mérito pelo Plenário do STF. (BRASIL, 2012). Em termos de andamento processual, consta no sítio eletrônico do STF, que os autos foram conclusos para a Ministra em 8 de janeiro de 2015 e, a entrega de relatório se deu no dia 26 de fevereiro de 2016 . 
MODIFICAÇÕES LEGISLATIVAS E IMPACTOS NOS ROYALTIES E NA PARTICIPAÇÃO ESPECIAL DESTINADOS AOS ÓRGÃOS DA ADMINISTRAÇÃO DIRETA

\subsection{Participação Especial}

$\mathrm{O}$ art. $50^{\circ}$ da Lei do Petróleo prevê o regime jurídico da participação especial, que foi regulamentado pelo Decreto ${ }^{\circ} 2.705$, de 3 de agosto de $1998^{4}$ (BRASIL, 1999). Essa receita será estabelecida no edital de licitação a ser publicado em momento oportuno pela Agência Nacional de Petróleo, Gás Natural e Biocombustíveis (ANP), assim como no contrato de concessão a ser firmado pelo Concessionário e o Poder Concedente, sendo prescrita em duas situações: nos casos de grande produção ou de grande rentabilidade, com as deduções previstas em Lei5.

As alíquotas são progressivas e incidem sobre a receita líquida da produção trimestral de cada campo, de acordo com a localização da lavra, o número de anos de produção e o respectivo volume de produção trimestral fiscalizada.

Os beneficiários na redação original da Lei Petróleo eram o MME, na proporção de $40 \%$ da produção; o MMA, no percentual de $10 \%$ da produção; os estados produtores ou confrontantes na razão de $40 \%$, e, os municípios produtores ou confrontantes no montante de 10\%. (BRASIL, 1999).

As regras contidas na Lei $n^{\circ}$ 12.734/2012 alteraram a distribuição da participação especial, e a parcela que caberia à administração direta da União (MME e MMA) foi destinada integralmente ao FS. (BRASIL, 2012). Regulamentação editada posteriormente pela União poderá indicar os órgãos da administração direta como beneficiários e, com isso, parte desses recursos serão enviados para o FS com as deduções correspondentes. Contudo, até o momento não existe regulamentação da União sobre essa matéria.

\section{DESTINAÇÃO DAS PARTICIPAĈ̃ES GOVERNAMENTAIS PARA OS ORGÃOS DA ADMINISTRAÇÃO PÚBLICA FEDERAL}

Conforme exposto, parcelas significativas das receitas de royalties e de participação especial eram destinadas aos órgãos da administração direta da União. Os recursos destinados ao Comando da Marinha tinham como finalidade custear os encargos de fiscalização e proteção das áreas de produção. (COSTA, 2012). Já os recursos destinados ao MCTI eram aplicados no financiamento de programas de amparo à pesquisa científica e desenvolvimento tecno- 
lógico aplicáveis à cadeia de hidrocarbonetos e de biocombustíveis, bem como à indústria petroquímica de primeira e segunda geração. Os royalties também poderiam ser destinados a programas que tenham por finalidade a prevenção e a recuperação de danos causados ao meio ambiente.

Ademais, a redação do parágrafo primeiro do art. $49^{\circ}$ da Lei do Petróleo prescrevia que do total de recursos destinados ao MCTI, no mínimo, $40 \%$ seriam aplicados em programas de fomento à capacitação e ao desenvolvimento científico e tecnológico das regiões Norte e Nordeste. Por meio da Lei $\mathrm{n}^{\circ} 11.540$, de12 de novembro de 2007, foi introduzido um enfoque relativo às respectivas áreas de abrangência das Agências de desenvolvimento regional do Norte e Nordeste. (BRASIL, 2007).

Quanto à participação especial destinada ao MME, 70\% tinham como finalidade o financiamento de estudos e serviços de geologia e geofísica aplicáveis à prospecção de combustíveis fósseis, promovidos pela ANP; $15 \%$ para o custeio dos estudos de planejamento da expansão do sistema energético e $15 \%$ para o financiamento de estudos, pesquisas, projetos, atividades e serviços de levantamentos geológicos básicos no território nacional.

No tocante ao volume de recursos designado para o MMA, a previsão de destinação esboçada pela redação original da Lei do Petróleo focalizava o desenvolvimento de estudos e projetos relacionados à preservação do meio ambiente e recuperação de danos ambientais inerentes à indústria do petróleo. Nesse contexto, cabe ressaltar que a Lei $\mathrm{n}^{\circ}$ 12.114, de 9 de dezembro de 2009 incluiu uma série de áreas tidas como prioritárias para a destinação da participação especial do MMA. (BRASIL, 2009).

Oberva-se que o Poder Executivo Federal, por meio de seus ministérios elencados nas leis comentadas, seria responsável por destinar as participações governamentais recebidas para a realização de políticas públicas específicas. Ocorre que, a alteração promovida pela Lei $n^{0} 12.734 / 2012$ e a revogação desses dispositivos, os órgãos citados perderam parcela importante de suas fontes de receitas, o que implicou em escassez de recursos, cuja análise mais detida será realizada a seguir. 
MODIFICAÇÕES LEGISLATIVAS E IMPACTOS NOS ROYALTIES E NA PARTICIPAÇÃO ESPECIAL DESTINADOS AOS ÓRGÃOS DA ADMINISTRAÇÃO DIRETA

\subsection{Redistribuição da destinação das Receitas de Royalties e participação especial no âmbito da União}

Ao se pesquisar o volume de recursos recolhido e destinado aos beneficiários, foi possível extrair do banco de dados do Info Royalties (UNIVERSIDADE CANDIDO MENDES, 2016), os valores percebidos a título de royalties pelo CM, pelo MCTI, MMA, MME e pelo FS do Petróleo, conforme denotam os dados do Gráfico 1.

Gráfico 1 - Royalties e participação especial destinados ao MCTI, Comando da Marinha, MME, MMA e Fundo Social em milhões de reais (2012-2016), corrigidos pelo IGP-DI (2016)

\begin{tabular}{|c|c|c|c|c|c|c|c|}
\hline \multirow{2}{*}{$\begin{array}{l}\text { Origem } \\
\text { das } \\
\text { receitas }\end{array}$} & \multirow{2}{*}{$\begin{array}{l}\text { Destino das } \\
\text { receitas }\end{array}$} & \multicolumn{2}{|c|}{ Partilha } & \multicolumn{2}{|c|}{$\begin{array}{c}\text { Concessão } \\
\text { (5\% obrigatório) }\end{array}$} & \multicolumn{2}{|c|}{$\begin{array}{l}\text { Concessão } \\
\text { (5\%e 10\%) }\end{array}$} \\
\hline & & $\begin{array}{c}\text { Norma } \\
\text { Atual }\end{array}$ & \begin{tabular}{|c|} 
Norma \\
Anterior
\end{tabular} & $\begin{array}{c}\text { Norma } \\
\text { Atual }\end{array}$ & \begin{tabular}{|c|} 
Norma \\
Anterior
\end{tabular} & $\begin{array}{c}\text { Norma } \\
\text { Atual }\end{array}$ & $\begin{array}{c}\text { Norma } \\
\text { Anterior }\end{array}$ \\
\hline \multirow{2}{*}{ 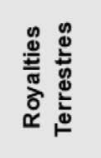 } & Fundo Social & $15 \%$ & $\begin{array}{l}\text { Não } \\
\text { tratava }\end{array}$ & 0 & 0 & $25 \%$ & $\begin{array}{l}\text { Não } \\
\text { tratava }\end{array}$ \\
\hline & $\begin{array}{c}\text { Ministério da } \\
\text { Marinha }\end{array}$ & 0 & $\begin{array}{l}\text { Não } \\
\text { tratava }\end{array}$ & $\begin{array}{l}\text { Não } \\
\text { trata }\end{array}$ & 0 & $\begin{array}{l}\text { Não } \\
\text { trata }\end{array}$ & $25 \%$ \\
\hline \multirow{3}{*}{ 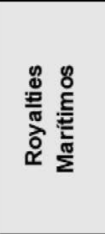 } & Fundo Social & $22 \%$ & $\begin{array}{l}\text { Não } \\
\text { tratava }\end{array}$ & $20 \%$ & 0 & $20 \%$ & $\begin{array}{l}\text { Não } \\
\text { tratava }\end{array}$ \\
\hline & $\begin{array}{l}\text { Ministério da } \\
\text { Marinha }\end{array}$ & 0 & $\begin{array}{l}\text { Não } \\
\text { tratava }\end{array}$ & $\begin{array}{l}\text { Não } \\
\text { trata }\end{array}$ & $20 \%$ & $\begin{array}{l}\text { Não } \\
\text { trata }\end{array}$ & $15 \%$ \\
\hline & $\begin{array}{c}\text { Ministério da } \\
\text { Ciência e } \\
\text { Tecnologia }\end{array}$ & 0 & $\begin{array}{l}\text { Não } \\
\text { tratava }\end{array}$ & $\begin{array}{l}\text { Não } \\
\text { trata }\end{array}$ & $\begin{array}{l}\text { Não } \\
\text { tratava }\end{array}$ & $\begin{array}{l}\text { Não } \\
\text { trata }\end{array}$ & $25 \%$ \\
\hline
\end{tabular}

Fonte: Elaboração própria, a partir de: UNIVERSIDADE CANDIDO MENDES. Info Royalties. Rio de Janeiro, 2016. Banco de Dados sobre distribuição de royalties no Brasil. Disponível em: $<\mathrm{http}: / /$ inforoyalties.ucam-campos.br/informativo.php>. Acesso em: 31 jan. 2017.

Como se observa, a partir dos dados do Gráfico 1, os valores percebidos pela Marinha tiveram acréscimos ao longo do período 2000-2006, possivelmente resultado do crescimento de 39,69\% do volume de produção nacional de petróleo na plataforma continental no mesmo período. Depreende-se, portanto, que a oscilação das receitas destinadas à Marinha, entre os anos de 2007 e 2012, foi influenciada pelo preço internacional do barril do petróleo e pelo câmbio, pois o crescimento da produção nacional em barris equivalentes de petróleo nesse período foi de 11,58\%.

Nesse sentido, em 2008, os valores repassados para a Marinha atingiram o ápice de R $\$ 1,79$ bilhão. Diferente do que ocorreu 
em 2009, quando o repasse sofreu uma queda de $27,53 \%$ em relação ao ano anterior. Contrariamente, o crescimento do volume de petróleo, nesse mesmo período, foi de 7,33\%. (AGÊNCIA NACIONAL DE PETRÓLEO, GÁS NATURAL E BIOCOMBUSTÍVEIS, 2017; COSTA, 2012). A partir de 2012, percebe-se, de acordo com o Gráfico 1, o declínio dos royalties percebidos.

Em relação ao MCTI, os valores percebidos a título de royalties também sofreram acréscimos ao longo do período 2000-2006, em razão do crescimento do volume de produção nacional de petróleo. (AGÊNCIA NACIONAL DE PETRÓLEO, GÁS NATURAL E BIOCOMBUSTÍVEIS, 2017). Todavia, em 2007, verificou-se uma leve redução, com a recuperação ocorrida em 2008, com a arrecadação de R \$ 1,41 bilhão. Esse cenário muda a partir de 2012, com declínios significativos no período 2013-2016.

Já os resultados da arrecadação da participação especial, durante o período 1999-2016, para o MME e MMA, como já explicado, as receitas de participação especial, por sua própria definição, são devidas em casos de grande volume ou rentabilidade, portanto, serão bacias específicas que proporcionarão a percepção dessa receita.

Averigua-se que os valores de participação especial destinados ao MME se expandiram em 204\% durante o período 2000-2005. Todavia, no período compreendido entre 2006-2007 sofreram queda de $39 \%$ em relação ao ano de 2005 e, a partir de 2008, verificou-se recuperação que culminou no incremento de aproximadamente $85 \%$ de percepção de valores referentes à participação especial, comparando-se 2009 ao ano de 2007. Durante o período 2009-2011, houve elevação, e, posteriormente, a partir de 2012, ou seja, após a entrada em vigor das Leis $n^{\circ} 12.351 / 2010$ e $n^{\circ} 12.734 / 2012$, verificaram-se quedas significativas.

As receitas da ordem de R \$ 4,1 bilhões, em 2009, comprovavam a pujança do percentual de participação especial direcionada ao MME. Por exemplo, em termos de dotação orçamentária prevista para o mesmo período, o total de receita proveniente somente do tesouro e de outras fontes constante do Anexo II, da Lei Orçamentária Anual no 11.897, de 30 de dezembro de 2008 foi de, aproximadamente, R\$ 7,1 bilhões para o MME (ASSOCIAÇÃO CONTAS ABERTAS, 2008, [20--?]b, [20--?]b). 
MODIFICAÇÕES LEGISLATIVAS E IMPACTOS NOS ROYALTIES E NA PARTICIPAÇÃO ESPECIAL DESTINADOS AOS ÓRGÃOS DA ADMINISTRAÇÃO DIRETA

Sendo assim, em 2009, os recursos oriundos da participação especial constantes no Gráfico 1 representaram por volta de $59 \%$ do total das receitas provenientes somente do Tesouro e de outras fontes previstas na Lei Orçamentária Anual no 11.897/2008 para o MME (ASSOCIAÇÃO CONTAS ABERTAS, 2008, [20--?]b, [20--?]b). Considerando o valor corrente, em 2009, de participação especial, essa relação ficou em 54\%.

Para o MMA, é possível verificar no Gráfico 1 um período inicial, de 2000 a 2005 , com valores relativamente dentro do patamar de milhões de reais, crescendo $155 \%$. Após o ápice do ano de 2006, os anos seguintes foram de decréscimo de receitas na ordem de $11 \%$ que, todavia, permaneceram na faixa de bilhões de reais. Todavia, as receitas direcionadas ao MMA decresceram de forma significativa no período 2012-2016.

\subsection{O Fundo Social}

A Lei ${ }^{\circ} 12.351 / 2010$, em seu art $47^{\circ}$, criou o FS, in verbis:

de natureza contábil e financeira, vinculado à Presidência da República, com a finalidade de constituir fonte de recursos para o desenvolvimento social e regional, na forma de programas e projetos nas áreas de combate à pobreza, e de desenvolvimento:I - da educação;II - da cultura;III - do esporte;IV - da saúde pública;V - da ciência e tecnologia;VI - do meio ambiente; e, VII - de mitigação e adaptação às mudanças climáticas. Parágrafo Primeiro: os programas e projetos de que trata o caput observarão o plano plurianual - PPA, a lei de diretrizes orçamentárias - LDO e as respectivas dotações consignadas na lei orçamentária anual - LOA. (BRASIL, 2010b).

Constata-se que, no referido artigo, o legislador premiou políticas públicas de desenvolvimento humano e tecnológico, bem como ações focalizadas na relação do homem com a natureza.

Todavia, o art. $48^{\circ}$ dispõe sobre os objetivos do FS, que enquadram além dessas áreas prioritárias, a constituição de poupança pública e a mitigação das flutuações de renda e de preços na economia nacional. Com isso, é possível questionar como será realizada a alocação de recursos entre as áreas do art. $47^{\circ}$ e os objetivos do FS constantes do art. $48^{\circ}$, que são mais amplos. Por exemplo, qual o trade-off entre destinar os recursos para o gasto em desenvolvimento da educação e, ao mesmo tempo, constituir poupança pública? 
Em certa medida, questiona-se porque não tentar diminuir as carências estruturais e sociais do país, hoje, ao invés de poupar recursos. (COSTA, 2012).

A resposta a essa pergunta vem no art. $51^{\circ}$, cujo teor é: “[...] os recursos do FS para aplicação nos programas e projetos a que se refere o art. 47 deverão ser os resultantes do retorno sobre o capital." (BRASIL, 2010b). Contudo, o percentual resgatado anualmente pelo fundo seria suficiente para cobrir as demandas das áreas do art. $47^{\circ}$ ?

Para mitigar a regra do art. $51^{\circ}$, o seu parágrafo único definiu que: "[...] constituído o FS e garantida a sua sustentabilidade econômica e financeira, o Poder Executivo, na forma da lei, poderá propor o uso de percentual de recursos do principal para a aplicação nas finalidades previstas no art. 47, na etapa inicial de formação de poupança do fundo". (BRASIL, 2010b).

Ocorre que, ao se pensar na escolha econômica de destinação de recursos entre finalidades do art. $47^{\circ}$ e poupança pública, deve-se ter em mente a realidade de desigualdades social e regional existentes no país. Nesse sentido, necessário se faz reconhecer as demandas sociais do Brasil.

Ademais, não obstante as problemáticas levantadas sobre os objetivos a serem agasalhados pelo FS, é necessário pensar no próprio conteúdo do art. $47^{\circ}$, uma vez que sua generalidade torna necessária a realização de delimitações conceituais e metodológicas.

Considerando a importância de políticas públicas inclusivas, indagações relativas ao art. $47^{\circ}$ seriam do seguinte tipo: quais as formas de pobreza que os recursos do fundo irão combater? A pobreza tem diversos matizes; uma leitura que vincula o conceito de pobreza exclusivamente à renda per capita, por exemplo, pode não resolver 0 problema estrutural que historicamente persiste no país.

Metodologicamente, como os recursos do FS podem colaborar para a redução da pobreza? Quais as metas e os prazos para o proposto? E, como avaliar e monitorar os projetos e programas voltados à redução da pobreza?

Dentro da sistemática da Lei $\mathrm{n}^{\circ} 12.351 / 2010$, nota-se que os recursos do FS serão destinados ao financiamento de programas e projetos definidos como prioritários pelo Conselho Deliberativo do Fundo Social (CDFS), órgão gestor do FS, dentro do critério de redução das desigualdades regionais, condicionados à prévia fixação 
MODIFICAÇÕES LEGISLATIVAS E IMPACTOS NOS ROYALTIES E NA PARTICIPAÇÃO ESPECIAL DESTINADOS AOS ÓRGÃOS DA ADMINISTRAÇÃO DIRETA

de metas, prazos de execução e planos de avaliação, consentâneo com as disposições estabelecidas no Plano Plurianual (PPA).

Igualmente, o CDFS deverá submeter os projetos e programas à criteriosa avaliação quantitativa e qualitativa durante todas as fases de execução, com o monitoramento de impactos efetivos sobre a população e nas regiões de intervenção, sendo que instituições públicas e universitárias poderão apoiá-lo. Contudo, a lei não diz como esse apoio será viabilizado, igualmente não delimita, claramente, o papel que essas instituições desempenhariam na avaliação e no monitoramento.

Como se percebe, portanto, a Lei deixa para o CDFS a função de propor, ao Poder Executivo, ouvidos Ministérios afins, conceitos e metodologias para a destinação dos recursos do FS, cabendo-lhe o desenho de programas e de projetos amparados nas áreas do art. $47^{\circ}$, observados o PPA, a Lei de Diretrizes Orçamentárias (LDO) e a Lei Orçamentária Anual (LOA). Contudo, algumas delimitações, também, serão objetos de decretos executivos regulamentadores posteriores, como por exemplo, a definição da composição, das competências e do funcionamento do CDFS.

Pode-se apontar que a generalidade do art. $47^{\circ}$, também, não deixa claro se os incisos estão estruturados em ordem de preferência, o que pode possibilitar uma ampla discussão sobre se existiriam setores preferenciais quando da escolha dos programas ou projetos. Por tal motivo, é recomendada a criação de um indicador que torne transparente as escolhas de programas e de projetos pelo CDFS, como também é importante a existência de um indicador de avaliação da aplicação desses recursos.

Dessa forma, os benefícios dos recursos do FS se estenderiam além da efetivação de direitos fundamentais e da proposta de alcance de uma sustentabilidade integral pela comunidade, para uma ampliação da perspectiva de cidadania e de democracia atualmente existentes, o que poderia resultar também na melhora do gasto público. Com tais direcionamentos, demonstrar-se-ia à população local que ela é responsável pela sustentabilidade dos recursos destinados aos seus territórios, bem como de sua economia local, e que através da participação direta e questionadora, os incrementos de direitos poderiam ser reais. 
Há de se registrar, também, a edição da Lei no 12.858 , de 9 de setembro de 2013, que destina 50\% dos recursos do FS para gastos com saúde e educação:

Art. $2^{\circ}$ Para fins de cumprimento da meta prevista no inciso VI do caput do art. 214 e no art. 196 da Constituição Federal, serão destinados exclusivamente para a educação pública, com prioridade para a educação básica, e para a saúde, na forma do regulamento, os seguintes recursos:

$[\ldots]$

III - 50\% (cinquenta por cento) dos recursos recebidos pelo Fundo Social de que trata o art. 47 da Lei no 12.351 , de 22 de dezembro de 2010, até que sejam cumpridas as metas estabelecidas no Plano Nacional de Educação [...]. (BRASIL, 2013a).

Observa-se que os recursos, os quais seriam originalmente destinados à formação do FS, passaram a ser aplicados diretamente em gastos correntes com saúde e educação, sem uma finalidade específica e por tempo indeterninado. Ou seja, verifica-se a partir da publicação dessa lei, a necessidade de edição de regulamentação para se qualificar o gasto público com educação e saúde.

Todavia, em certa medida, pode-se dizer que esse redirecionamento, dado pela Lei $\mathrm{n}^{\mathrm{0}}$ 12.858/2013, descaracteriza a função originalmente prevista para os recursos destinados ao FS, uma vez que adia a formação de uma poupança consolidada e, consequentemente, posterga a possibilidade de aplicação direcionada das receitas aos demais objetivos do fundo. Infere-se, portanto, a despeito do potencial beneficio dos gastos públicos com educação e saúde, que a partir da promulgação da Lei ${ }^{\circ} 12.858 / 2013$ há um claro risco de esvaziamento do FS.

\subsection{A mudança no perfil de gastos dos royalties e participação especial no âmbito federal}

Sabe-se que dentre os principais argumetnos para a cobrança de royalties e participações especiais decorrentes da exploração de hidrocarbonetos está o que se conhece por justiça intergeracional, assegurada no art. $225^{\circ}$ da CF. Nesse sentido, uma vez que os recursos naturais vão sendo esgotados paulatinamente, cabe ao Estado procurar meios de transformar sua exploração em capital que beneficie as futuras gerações. 
MODIFICAÇÕES LEGISLATIVAS E IMPACTOS NOS ROYALTIES E NA PARTICIPAÇÃO ESPECIAL DESTINADOS AOS ÓRGÃOS DA ADMINISTRAÇÃO DIRETA

Não há necessariamente uma forma única de garantir que tais recursos alcancem as futuras gerações, pois nesse sentido a forma mais óbvia seria explorar menos recursos, deixando-os para futuras gerações, porém se deve levar em consideração que nada garante o seu valor no futuro. Por outro lado, outra resposta poderia ser poupar as receitas decorrentes da exploração de petróleo e gás, de forma que, quando esgotadas as reservas, outras gerações ainda possam usufruir de suas receitas.

Alternativa possível, e bem mais complexa, é a utilização dessas receitas para o desenvolvimento de capital humano, intelectual e ambiental, além de financiamento da diversificação das atividades econômicas do país. Sob esse ponto de vista, a ideia é que quando esgotados os recursos naturais, as gerações futuras encontrem outras fontes de financiamento econômico, podendo gozar de melhor infraestrutura e serviços essenciais.

Nesse aspecto, analisando a mudança de perfil de alocação das receitas de participação governamental da União após a vigência da Lei $\mathrm{n}^{\mathrm{O}} 12.351 / 2010$, o resultado parece ter sido pouco eficiente no que tange à promoção da justiça intergeracional.

Houve um decréscimo considerável de receitas de royalties e participação especial destinados aos órgãos da administração pública federal para o período analisado, sobretudo, após a entrada em vigor da Lei $\mathrm{n}^{\mathrm{o}}$ 12.734/2012. Mencionadas receitas foram redirecionadas ao FS, que, por sua vez, teve metade de seus recursos realocados para gastos correntes em saúde e educação, sem objetivo pré-definido. Como explica Serra (2006, p. 204), o que se observa nos últimos anos, ao analisar os gastos públicos, "[...] é que as participações governamentais estão sendo utilizadas pelos três níveis de governo, para financiar gastos correntes, com baixa capacidade de favorecimento às gerações futuras".

A realocação das receitas interrompeu importantes projetos, programas e políticas públicas que encontravam assento na égide da redação original da Lei do Petróleo, os quais eram realizados via órgãos da administração direta da União.

Nesse sentido, tem-se o exemplo do MMA, que possuía em sua agenda inúmeras destinações pautadas no princípio da justiça intergeracional, inclusive semelhantes ao disposto no art. $47^{\circ}$. Entre suas destinações estão projetos de mitigação e adaptação às 
mudanças climáticas, inferindo-se que as destinações do MMA na Lei do Petróleo são bem mais amplas do que as previstas na Lei ${ }^{\circ}$ 12.351/2010. (COSTA, 2012).

A determinação realizada pela Lei $n^{0} 12.351 / 2010$, em que as receitas anteriormente destinadas ao MMA, MME, MCTI, entre outros, agora destinadas a compor o FS podem cumprir os objetivos previstos em lei, desde que sejam promovidas as condições necessárias a fomentar um maior grau de independência das receitas decorrentes da exploração de hidrocarbonetos, alcançando, assim, um patamar de sustentabilidade financeira. Isso inclui soluções inteligentes para a crescente demanda de recursos naturais, com políticas energéticas substitutivas baseadas em energias provenientes de fontes alternativas, bem como em programas e projetos que primem pelo ideal de eficiência e conservação de energia. (COSTA, 2012).

Por fim, vale registrar, aqui, que há importantes discussões sobre a natureza e classificação das receitas públicas decorrentes de royalties e participação especial; se receitas correntes ou receitas de capital. A referida classificação tem como consequência a vinculação ou restrição de sua aplicação em determinado tipo de despesas ${ }^{6}$. Por exemplo, as chamadas receitas de capital não devem ser utilizadas em despesas correntes.

Apesar da relevância do debate, entende-se que restringir demais a forma de gasto não parece ser a melhor solução, uma vez que existem despesas correntes, que, apesar de assim classificadas, trata-se de verdadeiro investimento de longo prazo que alcança não só a geração presente, mas, também, as futuras gerações. Importante exemplo é o gasto com pesquisa e desenvolvimento pela União, o qual ficou bastante prejudicado com a redução dos recursos destinados à administração direta.

De todo modo, percebe-se que não basta a existência de receitas e o seu respectivo direcionamento às instâncias competentes; em termos legais, devem munir-se de um arcabouço conceitual e metodológico, vinculado a um efetivo sentido de desenvolvimento do ser humano, baseado no conhecimento da região, nas características locais, nas vocações, na cultura de cada municipalidade, na sustentabilidade e na efetivação de direitos fundamentais, bem como na avaliação de resultados dentro do que foi proposto enquanto objetivo de programas e de projetos. (COSTA, 2012). 
MODIFICAÇÕES LEGISLATIVAS E IMPACTOS NOS ROYALTIES E NA PARTICIPAÇÃO ESPECIAL DESTINADOS AOS ÓRGÃOS DA ADMINISTRAÇÃO DIRETA

\section{CONCLUSÃO}

A Lei $n^{\circ} 9.478 / 1997$, com a nova redação dada pelas Leis $n^{\circ}$ 12.351/2010 e n ${ }^{\circ}$ 12.734/2012, traz a inclusão do FS como beneficiário de royalties e de participação especial, em detrimento aos órgãos da administração pública direta.

Através do exame dos dados relativos aos MME, MMA, MCTI e Comando da Marinha, constante do Gráfico 1, verifica-se queda significativa nas receitas percebidas desde a entrada em vigor da Lei ${ }^{\circ}$ 12.351/2010 e parcial da Lei nº 12.734/2012.

Assim, com a revogação da destinação das receitas citadas para o MME, MMA, MCTI e CM, vislumbra-se a perda de efetividade de funções outrora criadas pela Lei do Petróleo, pela Lei ${ }^{\circ}$ 11.540/2007 e pela Lei $n^{\circ}$ 12.114/2009.

No que se refere às políticas públicas previstas no FS, ressalta-se que o governo pode escolher a constituição de poupança pública como prioridade. Para evitar esse direcionamento, é recomendável um equilíbrio entre constituição de poupança e gastos nas áreas do art. $47^{\circ}$. Há de se questionar se os resgates anuais seriam suficientes para cobrir a finalidade do FS, insculpida no art. $47^{\circ}$. Essa matéria, porém, se encontra vaga, posto ter ficado para regulamentação posterior a tarefa de definir os percentuais de resgates anuais.

A partir da edição da Lei $\mathrm{n}^{\circ}$ 12.858/2013, destinou-se 50\% dos recursos do FS para gastos com saúde e educação. Entretanto, esse redirecionamento descaracteriza a função originalmente prevista para os recursos destinados ao FS, porquanto adia a formação de uma poupança consolidada e do gasto com os demais objetivos do fundo.

Este artigo trouxe análises e discussões com o objetivo de contribuir enquanto literatura que tratou do tema em comento, sem, entretanto, esgotar suas diversas nuances e reconhecendo o desafio contínuo da construção conceitual e metodológica do direcionamento de receitas públicas em uma sociedade com tantas necessidades básicas que nem sequer foram atendidas.

\section{REFERÊNCIAS}

AGÊNCIA NACIONAL DE PETRÓLEO, GÁS NATURAL E BIOCOMBUSTÍVEIS. Dados estatísticos: produção de petróleo e gás natural - produção nacional de petróleo e LGN (barris equivalentes 
de petróleo). Rio de Janeiro, 2017. Disponível em: $<$ http://www.anp. gov.br/?pg $=57621 \& \mathrm{~m}=\& \mathrm{t} 1=\& \mathrm{t} 2=\& \mathrm{t} 3=\& \mathrm{t} 4=\& \mathrm{ar}=\& \mathrm{ps}=\& \mathrm{cachebu}$ $\mathrm{st}=1315493150723>$. Acesso em: 31 jan. 2017.

ASSOCIAÇÃO CONTAS ABERTAS. Execução por Órgão Superior: Ministério de Minas e Energia, Ministério de Ciência e Tecnologia, Ministério de Meio Ambiente, Recursos Hídricos e Amazônia, Comando da Marinha. [S. 1.], [20--?]a. Disponível em: <http://contasabertas.uol.com.br/WebSite/Orcamento/Uniao/ RelatorioResultado.aspx?Ano=2009\&Tipo=Orgao.$>$ Acesso em: 31 jan. 2017.

. Orçamento Geral da União (OGU) - 2009: compensação Financeira por Exploração de Petróleo ou Gás Natural. [S. 1.], [20--?] b. Disponível em: <http://contasabertas.uol.com.br/WebSite/Noticias/ imagens/SG_-_FONTE_142-342_-_ORGAO-UO-PROG_-_2009_ATE_27-08(1).pdf>. Acesso em:31 jan. 2017.

. Royalties: quase $80 \%$ é contingenciado. [S. 1.], 16 set. 2008. Disponível em: < http://www.contasabertas.com.br/website/ arquivos/2554>. Acesso em: 31 jan. 2017.

BRASIL. Câmara dos Deputados. Projeto de Lei 8.051, de 31 de dezembro de 2010. Dispõe sobre os royalties devidos em função da produção de petróleo, de gás natural e de outros hidrocarbonetos fluidos sob o regime de partilha de produção, em áreas do pré-sal e em áreas estratégicas, instituído pela Lei $\mathrm{n}^{\mathrm{o}} 12.351$, de 22 de dezembro de 2010, para os Estados, Distrito Federal, Municípios e órgãos da administração direta da União, e dá outras providências. Brasília, Df, 2010a. Disponível em:<http://www.camara.gov.br/proposicoesWeb/fi chadetramitacao?idProposicao=490372>. Acesso em: 31 jan. 2017.

Presidência da República. Lei 12.734, de 30 de novembro de 2012. Modifica as Leis oㅜ 9.478, de 6 de agosto de 1997, e ํㅜำ 12.351 , de 22 de dezembro de 2010, para determinar novas regras de distribuição entre os entes da Federação dos royalties e da participação especial devidos em função da exploração de petróleo, gás natural e outros hidrocarbonetos fluidos, e para aprimorar o marco regulatório sobre a exploração desses recursos no regime de partilha. Diário Oficial da União, Brasília, DF, ed. extra, 30 nov. 2012. Disponívelem: $<$ http://www.planalto.gov.br/ccivil_03/_Ato2011-2014/2012/Lei/ L12734.htm>.Acesso em:31 jan ${ }^{\circ} 2017$.

. Lei 12.858 , de 09 de setembro de 2013. Dispõe sobre a destinação para as áreas de educação e saúde de parcela da participação no resultado ou da compensação financeira pela 
MODIFICAÇÕES LEGISLATIVAS E IMPACTOS NOS ROYALTIES E NA PARTICIPAÇÃO ESPECIAL DESTINADOS AOS ÓRGÃOS DA ADMINISTRAÇÃO DIRETA

exploração de petróleo e gás natural, com a finalidade de cumprimento da meta prevista no inciso VI do caput do art. 214 e no art. 196 da Constituição Federal; altera a Lei no 7.990 , de 28 de dezembro de 1989; e dá outras providências. Diário Oficial da União, Brasília, DF, 10 set. 2013a. Disponível em: <http://www.planalto.gov.br/ccivil_03/_ Ato2011-2014/2013/Lei/L12858.htm>. Acesso em: 31 jan. 2017.

. Lei $\mathrm{n}^{\mathrm{o}} 11.540$, de 12 de novembro de 2007. Dispõe sobre o Fundo Nacional de Desenvolvimento Científico e Tecnológico - FNDCT; altera o Decreto-Lei no 719, de 31 de julho de 1969, e a Lei no 9.478, de 6 de agosto de 1997; e dá outras providências. Diário Oficial da União, Brasília, DF, 9 nov. 2007. Disponível em: $<$ http:// www.planalto.gov.br/ccivil_03/_Ato2007-2010/2007/Lei/L11540. $\mathrm{htm}>$. Acesso em: $31 \mathrm{jan}^{\circ} 2017$.

. Lei $\mathrm{n}^{\mathrm{o}} 12.114$, de 9 de dezembro de 2009. Cria o

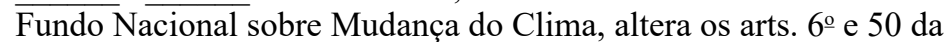
Lei no 9.478, de 6 de agosto de 1997, e dá outras providências. Diário Oficial da União, Brasília, DF, 10 dez. 2009. Disponível em: $<$ http:// www.planalto.gov.br/ccivil_03/_Ato2007-2010/2009/Lei/L12114. htm>. Acesso em: 31 jan. 2017.

. Lei $\mathrm{n}^{\mathrm{o}} 12.351$, de 22 de dezembro de 2010. Dispõe sobre a exploração e a produção de petróleo, de gás natural e de outros hidrocarbonetos fluidos, sob o regime de partilha de produção, em áreas do pré-sal e em áreas estratégicas; cria o Fundo Social - FS e dispõe sobre sua estrutura e fontes de recursos; altera dispositivos da Lei no 9.478, de 6 de agosto de 1997; e dá outras providências. Diário Oficial da União, Brasília, DF, 23 dez. 2010b. Disponível em: <http:// www.planalto.gov.br/ccivil_03/_Ato2007-2010/2010/Lei/L12351. $\mathrm{htm}>$ Acesso em: 31 jan. 2017.

. Lei n ${ }^{\text {o } 7.990, ~ d e ~} 28$ de dezembro de 1989. Institui,

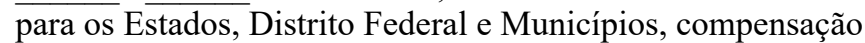
financeira pelo resultado da exploração de petróleo ou gás natural, de recursos hídricos para fins de geração de energia elétrica, de recursos minerais em seus respectivos territórios, plataformas continental, mar territorial ou zona econômica exclusiva, e dá outras providências. (Art. 21, XIX da CF). Diário Oficial da União, Brasília, DF, 29 dez. 1989. Disponível em: $<$ http://www.planalto.gov.br/ccivil_03/leis/ L7990.htm>. Acesso em: 31 jan. 2017.

Mensagem no 707, de 22 de dezembro de 2010. Diário Oficial da União, Brasília, DF, 23 dez. 2010c. Disponível 
em: $<$ http://www.planalto.gov.br/ccivil/_Ato2007-2010/2010/Msg/ VEP-707-10.htm>. Acesso em: 31 jan. 2017.

. Supremo Tribunal Federal. Em liminar, ministra Cármen Lúcia suspende dispositivos da nova lei dos royalties. Notícias STF, Brasília, DF, 18 mar. 2013b. Disponível em: <http://www.stf.jus.br/ portal $/ \mathrm{cms} /$ verNoticiaDetalhe. asp?idConteudo $=233758>$. Acesso em: 31 jan. 2017.

Medida Cautelar na Ação direta de Inconstitucionalidade $\mathrm{n}^{\circ}$ 4917. Relatora monocrática: Ministra Carmen Lúcia (Ministra). Brasília, DF, 2013b. Disponível em: $<$ http://www.stf. jus.br/portal/diarioJustica/verDiarioProcesso.asp?numDj $=54 \&$ dataPub licacaoDj $=21 / 03 / 2013 \&$ incidente $=4379392 \&$ codCapitulo $=6 \&$ numMa teria $=33 \&$ codMateria=2 $>$. Acesso em: 31 jan. 2017.

COSTA, H. K. M. O princípio da justiça intra e intergeracional como elemento na destinação das rendas de hidrocarbonetos: temática energética crítica na análise institucional brasileira. 2012. 346 f. Tese (Doutorado em Ciências) - Programa de Pós-Graduação em Energia, Universidade de São Paulo, São Paulo, 2012.

SERRA, R. V. Rendas petrolíferas no Brasil: critérios de distribuição distorcidos induzem ineficiência do gasto. In: MENDES, M. (Org.). Gasto público eficiente: 91 propostras para o desenvolvimento do Brasil. Rio de Janeiro: TOPBooks, 2006.

UNIVERSIDADE CANDIDO MENDES. Info Royalties. Rio de Janeiro, 2016. Banco de Dados sobre distribuição de royalties no Brasil. Disponível em:<http://inforoyalties.ucam-campos.br/ informativo.php>. Acesso em: 31 jan. 2017.

\section{Notas}

1 Os autores agradecem o suporte da BG E\&P Brasil e Fundação de Amparo à Pesquisa do Estado de São Paulo (FAPESP) através do Centro de Pesquisa e Inovação do Gás (FAPESP Proc. 2014/50279-4), assim como da Universidade de São Paulo (USP) e a importância estratégica do suporte dado pela Agência Nacional de Petróleo, Gás Natural e Biocombustíveis (ANP) através da cláusula de Pesquisa e Desenvolvimento (P\&D).

2 O primeiro despacho foi dado na ADI n ${ }^{\circ} 4916$ do Rio de Janeiro e os demais processos foram apensados ao primeiro.

3 A redação do art. $64^{\circ}$ da Lei n ${ }^{\circ} 12.351 / 2010$ que foi vetada pelo Presidente da República à época é a seguinte: "Ressalvada a participação da União, bem como a destinação prevista na alínea do inciso II do art. 49 da Lei no 9.478, de 6 de agosto de 1997, a parcela restante dos royalties e participações especiais oriunda dos contratos de partilha de produção ou de concessão de que trata a mesma Lei, quando a lavra ocorrer na plataforma continental, mar territorial ou zona econômica exclusiva, será dividida entre estados, Distrito Federal 


\section{MODIFICAÇÕES LEGISLATIVAS E IMPACTOS NOS ROYALTIES E NA PARTICIPAÇÃO ESPECIAL DESTINADOS AOS ÓRGÃOS DA ADMINISTRAÇÃO DIRETA}

e municípios da seguinte forma: I - 50\% (cinquenta por cento) para constituição de fundo especial a ser distribuído entre todos os estados e o Distrito Federal, de acordo com os critérios de repartição do Fundo de Participação dos Estados - FPE; e II - 50\% (cinquenta por cento) para constituição de fundo especial a ser distribuído entre todos os municípios, de acordo com os critérios de repartição do Fundo de Participação dos Municípios - FPM.§ $1^{\circ}$ A União compensará, com recursos oriundos de sua parcela em royalties e participações especiais, bem como do que lhe couber em lucro em óleo, tanto no regime de concessão quanto no regime de partilha de produção, os estados e municípios que sofrerem redução de suas receitas em virtude desta Lei, até que estas se recomponham mediante o aumento de produção de petróleo no mar. $\$ 20$ Os recursos da União destinados à compensação de que trata o $\S 10$ deverão ser repassados aos estados e municípios que sofrerem redução de suas receitas em virtude desta Lei, simultaneamente ao repasse efetuado pela União aos demais estados e municípios. $\$ 30$ Os royalties correspondem à participação no resultado da exploração de petróleo, de gás natural e de outros hidrocarbonetos fluidos de que trata $o$ $\S 1^{\circ}$ do art. 20 da Constituição Federal, vedada a sua inclusão no cálculo do custo em óleo, bem como qualquer outra forma de restituição ou compensação aos contratados, ressalvado o disposto no $\S 1$ o do art. 50 da Lei n ${ }^{\circ}$ 9.478, de 6 de agosto de 1997." (BRASIL, 2010b).

4 Esse Decreto define critérios para cálculo e cobrança das participações governamentais de que trata a Lei n 9.478/1997, aplicáveis às atividades de exploração, desenvolvimento e produção de petróleo e gás natural, e dá outras providências.

${ }^{5}$ As deduções estão referenciadas no parágrafo primeiro do art. $50^{\circ}$ da Lei do Petróleo, quais sejam: royalties, investimentos em exploração, custos operacionais, depreciação e os tributos previstos na legislação.

6 Essa discussão pode ser aprofundada com a leitura de: FERNANDES, A. G. T. Direito financeiro aplicado ao setor do petróleo. São Paulo: Ed. USP, 2013; BERCOVICI, G. Direito Econômico do Petróleo e dos Recursos Minerais. São Paulo: QuartierLatin, 2011; SCAFF, F. F. Royalties dopetróleo, minério e energia: aspectos constitucionais, financeiros e tributários. São Paulo: Revista dosTribunais, 2014; SILVEIRA, A. C. Governança pública de royalties: federalismo fiscal efuturas gerações. 2014. 392 f. Dissertação (Mestrado em Direito) - Faculdade de Direito, Universidade de São Paulo, São Paulo, 2014. 
